X-ray-i nduced def ects as obst acl es to di sl ocat i on not i on i $n$ al kal $i$ hal i de crystal s

\begin{tabular}{|l|l|}
\hline 著者 & Kohzuki Yohi chi , Ohgaku Tom yasu \\
\hline $\begin{array}{l}\text { j our nal or } \\
\text { publ i cat i on t i t l e }\end{array}$ & Journal of Nat er i al s Sci ence \\
\hline vol une & 52 \\
\hline number & 7 \\
\hline page $\mathrm{r}$ ange & 3959-3966 \\
\hline year & 2017- 04 01 \\
\hline URL & ht t p: //hdl . handl e. net /2297/46783 \\
\hline
\end{tabular}




\title{
Revised paper
}

\section{Title page}

\section{X-ray induced defects as obstacles to dislocation motion in alkali halide crystals}

\author{
Y. Kohzuki ${ }^{1,}{ }_{\star}$ and T. Ohgaku ${ }^{2}$
}

${ }^{1}$ Department of Mechanical Engineering, Saitama Institute of Technology, Saitama, Japan E-mail: kohzuki@sit.ac.jp

${ }^{2}$ Graduate School of Natural Science and Technology, Kanazawa University, Kanazawa, Japan E-mail: ogk@po3.nsknet.or.jp

Address correspondence to E-mail: kohzuki@sit.ac.jp (telephone number:

$+81-48-585-6907)$

Keywords: X-ray irradiation; point defects; dislocation; ultrasonic oscillatory stress; activation energy. 


\title{
X-ray induced defects as obstacles to dislocation motion in alkali halide crystals
}

\author{
Y. Kohzuki ${ }^{1,}{ }_{\star}$ and T. Ohgaku ${ }^{2}$ \\ ${ }^{1}$ Department of Mechanical Engineering, Saitama Institute of Technology, \\ Saitama, Japan \\ ${ }^{2}$ Graduate School of Natural Science and Technology, Kanazawa University, \\ Kanazawa, Japan
}

\begin{abstract}
$\mathrm{NaBr}$ and $\mathrm{KBr}$ single crystals were exposed to X-ray (W-target, $30 \mathrm{kV}, 20 \mathrm{~mA}$ ) at room temperature and strain-rate cycling tests associated with ultrasonic oscillation were carried out for the crystals at 77 to $293 \mathrm{~K}$. The stress decrement $(\Delta \tau)$ due to oscillation and the stress change due to strain-rate cycling have been measured during plastic deformation. The relative curve of $\Delta \tau$ and strain-rate sensitivity $(\lambda)$ of flow stress has a stair-like shape for the two kinds of crystals. That is to say, the curve has two bending points and is divided into three regions: two plateau regions and the region between the two bending points, where $\lambda$ decreases gradually with increasing $\Delta \tau$. The first region is a plateau within the small $\Delta \tau$. This implies that X-ray induced defects have weak interaction with dislocation and act as obstacles to dislocation motion. Furthermore, the dependence of stress decrement $\left(\tau_{\mathrm{p}}\right)$ at the first bending point on the activation volume $(V)$ obtained from the difference between $\lambda$ in the first and second plateau regions reflects the interaction between dislocation and defects induced by the $\mathrm{X}$-irradiation. The activation energy for the break-away of a dislocation from the defect could be obtained on the basis of $\tau_{\mathrm{p}}-V$ curve fitting the Barnett model to the experimental results. Then, the values of activation energy are 0.76 and $0.81 \mathrm{eV}$ for $\mathrm{NaBr}$ and for $\mathrm{KBr}$, respectively.
\end{abstract}

\section{Introduction}

Stress-strain curve is altered drastically by electron irradiation. The effect generally increases with increasing electron dosage, decreasing irradiation temperature and decreasing test temperature. The yield stress and the strain-rate sensitivity of flow stress increase with the irradiation dose [1]. It is well known that alkali halide crystals harden when they are exposed to X-ray irradiation [2-5]. This is because lattice defects induced by X-ray irradiation obstruct dislocation motion. The defect is electron-center 
or hole-center such as F-center, $\mathrm{V}_{2^{-}}$or $\mathrm{V}_{3}$-center. The interaction between dislocation and the defect is not clearly established yet. Interaction between dislocation and point defects has been widely investigated by the yield stress measurements (e.g., ref. [6, 7]), the direct observations of dislocation (e.g., ref. [8, 9]), the internal friction measurements (e.g., ref. [10, 11]), or the stress relaxation tests (e.g., ref. [12, 13]) so far. However, these widely well-known methods have some weak points as follows. Yield stress depends on dislocation velocity, dislocation density, and multiplication of dislocations [14]. With regard to the direct observations, electron microscopy is useful for a thin specimen but not for bulk, and also light scattering method provides the information on the a transparent specimen. Internal friction measurements concern the motion of the dislocation which breaks away from the weak obstacles such as impurities between two forest dislocations with vibration [15]. This is not for dislocation motion during plastic deformation. As for stress relaxation tests, it is assumed that internal structure of crystals does not change, i.e. dislocation density and internal stress are constant. These are the reasons why it is difficult to study dislocation-point defects interaction in bulk during plastic deformation. But the original method (the strain-rate cycling tests during the Blaha effect) is considered to break through the weak points in the widely known methods and has the merit different from these methods. The Blaha effect is the phenomenon that the static flow stress is decreased when ultrasonic oscillations are superimposed during plastic deformation. It has been reported so far that the measurement of strain-rate sensitivity under application of ultrasonic oscillatory stress during plastic deformation gives useful information on the interaction between a mobile dislocation and point defects in alkali halide crystals [16-18]. We report the interaction between dislocation and defects induced by X-ray irradiation in $\mathrm{NaBr}$ and 
$\mathrm{KBr}$ single crystals through the use of data obtained by the strain-rate cycling tests associated with ultrasonic oscillation.

\section{Experimental procedure}

The specimens, which were prepared by cleaving out of single crystalline ingots to the size of $5 \times 5 \times 15 \mathrm{~mm}^{3}$, were kept at $973 \mathrm{~K}$ for $20 \mathrm{~h}$ and were cooled to room temperature at the rate of $40 \mathrm{~K} / \mathrm{h}$. The specimens were exposed to $\mathrm{X}$-ray for $3 \mathrm{~h}$ on each of the pair wide surfaces at room temperature. The total exposure time is $6 \mathrm{~h}$. The irradiation was carried out with X-rays from W-target operated at $30 \mathrm{kV}$ and $20 \mathrm{~mA}$ by

Figure 1 a Shimadzu XD-610. Fig. 1 shows the absorption spectrum of the X-ray irradiated $\mathrm{NaBr}$ and $\mathrm{KBr}$, which was measured with a Hitachi U-3500 spectrophotometer. Seitz $[19,20]$ has reported the color center of alkali halide. The peak of F-band (2.3 eV) is seen in the spectra of $\mathrm{X}$-ray irradiated $\mathrm{NaBr}$. The peak above $6 \mathrm{eV}$ is attributed to $\mathrm{OH}^{-}$ [21]. In the spectra of the X-ray irradiated $\mathrm{KBr}$, the peak of $\mathrm{F}-(2.0 \mathrm{eV})$ band is seen and the peak of $4.7 \mathrm{eV}$ is attributed to $\mathrm{V}_{2}$-band. The average concentration of F-centers, which was estimated from the Smakula formula [22], is $15 \times 10^{16} \mathrm{~cm}^{-3}$ for $\mathrm{NaBr}$ and 13 $\times 10^{16} \mathrm{~cm}^{-3}$ for $\mathrm{KBr}$.

Figure 2 A schematic illustration of the apparatus is shown in Fig. 2. A resonator composed of a vibrator and a horn with the resonant frequency of $20 \mathrm{kHz}$ was attached to a Shimadzu DSS-500 testing machine. The specimens were lightly fixed on a piezoelectric transducer and then cooled down to a test temperature. The specimens were deformed by compression along the $<100>$ axis and the ultrasonic oscillatory stress was intermittently superimposed for one or two minutes by the resonator in the 
same direction as the compression. The amplitude of the oscillatory stress was monitored by the output voltage from the piezoelectric transducer. The strain of the specimen is considered to be homogeneous, because the wavelength, which is $167 \mathrm{~mm}$ for $\mathrm{NaBr}$ and $152 \mathrm{~mm}$ for $\mathrm{KBr}$ by calculating from the data of ref. [23], is about $10 \sim 11$ times as long as the length of the specimen.

Figure 3 The strain-rate cycling test during the Blaha effect measurement is illustrated in Fig. 3. Superposition of oscillatory stress $\left(\tau_{\mathrm{v}}\right)$ during plastic deformation causes a stress drop $(\Delta \tau)$. Keeping the stress amplitude of $\tau_{\mathrm{v}}$ constant, strain-rate cycling between the strain rates of $\dot{\varepsilon}_{1}\left(1.1 \times 10^{-5} \mathrm{~s}^{-1}\right)$ and $\dot{\varepsilon}_{2}\left(5.6 \times 10^{-5} \mathrm{~s}^{-1}\right)$ was carried out at $77 \mathrm{~K}$ to room temperature. Then, the stress change due to the strain-rate cycling is $\Delta \tau^{\prime}$. For the tests at $77 \mathrm{~K}$, the specimen was immersed in the liquid nitrogen. The other temperature measurements were made by thermocouples of $\mathrm{Ni}-55 \% \mathrm{Cu}$ vs. $\mathrm{Cu}$. Each specimen was held at the test temperature for 30 min prior to the compression test and the stability of temperature during the test was kept within $2 \mathrm{~K}$. The strain-rate sensitivity $\left(\Delta \tau^{\prime} / \Delta \ln \dot{\varepsilon}\right)$ of the flow stress, which is given by $\Delta \tau^{\prime} / 1.609$, was used as a measure of the strain-rate sensitivity $\left(\lambda=\Delta \tau^{\prime} / \Delta \ln \dot{\varepsilon}\right)$.

\section{Results and discussion}

\section{Relation between $\Delta \tau$ and $\lambda$}

Figure 4a,b Fig. 4a for $\mathrm{X}$-ray irradiated $\mathrm{NaBr}$ at $173 \mathrm{~K}$ shows that $\Delta \tau$ does not change significantly with shear strain but increases with stress amplitude at a given temperature and shear strain. Fig. $4 \mathrm{~b}$ shows that $\lambda$ decreases with stress amplitude and the variation of it with $\tau_{\mathrm{v}}$ is small at low and high amplitudes. The $\lambda$ increases with shear strain due to the 
increase of the forest dislocation density. The values of $\lambda$ and $\Delta \tau$ obtained from

Figure 5 Fig. 4a and b at shear strains of 15 and $20 \%$ are plotted in Fig. 5 as the relation between $\lambda$ and $\Delta \tau$ for the given internal structure. The variation of $\lambda$ with $\Delta \tau$ is stair-like. That is to say, there are two bending points and two plateau regions: the first plateau region ranges below the first bending point at low stress decrement and the second one extends from the second bending point at high stress decrement. The $\lambda$ decreases gradually with increasing $\Delta \tau$ between the two bending points. The value of $\Delta \tau$ at the first bending point is referred to as $\tau_{\mathrm{p}}$ in Fig. 5. As given in the below description the relative curve between $\Delta \tau$ and $\lambda$ reflects the effect of ultrasonic oscillation on the dislocation motion on the slip plane containing many weak obstacles and a few forest dislocations during plastic deformation, which was detailed in the paper [18]. Within the first plateau region of $\Delta \tau$ versus $\lambda$ curve in low $\Delta \tau$, the application of oscillation with low stress amplitude cannot influence the average length of dislocation segments $(\bar{l})$ and $\bar{l}$ is considered to remain constant. All weak obstacles act as impedimenta to the dislocation motion in the region. Appling oscillation with higher stress amplitude, the dislocation begins to break-away from the weak ones between the forest dislocations and $\bar{l}$ begins to increase. Then, the $\lambda$ of flow stress starts to decrease at the first bending point $\tau_{\mathrm{p}}$, since $\lambda$ is inversely proportional to $\bar{l}$ [24]. Some weak obstacles stop Figure 6 acting as impedimenta there. $\lambda_{\mathrm{p}}$ denoted in the figure is introduced later. Fig. 6 shows the influence of temperature on the relationship between $\lambda$ and $\Delta \tau$ for the $\mathrm{KBr}$ crystals. $\tau_{\mathrm{p}}$ tends to be lower as the temperature is larger and disappears at room temperature.

Figure 7 Fig. 7 corresponds to the case for non-irradiated $\mathrm{KBr}$ single crystals at $193 \mathrm{~K}$. This figure represents the influence of shear strain on the relation between $\lambda$ and $\Delta \tau$. The 
relative curve shifts upward with increasing shear strain. This phenomenon is caused by the part of the $\lambda$ which depends on dislocation cuttings. Furthermore, there is only one bending point on each curve in contrast to the irradiated $\mathrm{KBr}$ crystals, which is considered to correspond to second bending point as shown in Figs 5 and 6 . The relative curve for the irradiated $\mathrm{KBr}$ crystal has first bending point at near $193 \mathrm{~K}$ as shown in Fig. 6. Similar result is obtained also for the $\mathrm{NaBr}$ crystals at low temperature. This implies that the first bending point becomes to appear on the relative curve at low temperatures by irradiating $\mathrm{NaBr}$ and $\mathrm{KBr}$. So far, the first bending point, $\tau_{\mathrm{p}}$, at low stress decrement has been considered to represent the effective stress due to the weak obstacles such as the dopant ions which lie on the dislocation when a dislocation begins to break-away from the weak obstacles with the help of oscillation during plastic deformation of alkali halide doped with monovalent or divalent ions [16-18]. The weak obstacles are considered to be the X-ray induced defects here. Therefore, $\tau_{\mathrm{p}}$ in this study corresponds to the effective stress due to the defects. The difference between $\lambda$ at the first plateau place and that at the second one, $\lambda_{\mathrm{p}}$ defined in Fig. 5, has been regarded as a component of $\lambda$ due to point defects [25]. And $\lambda_{\mathrm{p}}$ is related to the inverse of the average spacing, $l_{\mathrm{p}}$, of point defects along dislocation (i.e. activation volume, $V$, for the thermally activated dislocation motion) at a given temperature, $T$, as given in the following equation:

$$
\lambda_{p}=\frac{k T}{b l_{p} d}
$$

where $k$ is the Boltzmann constant, $b$ the magnitude of Burgers vector, and $d$ the 
activation distance.

Nadeau [3, 26] reported on several alkali halide crystals subjected to $\gamma$-ray irradiation as below: the flow stress increase due to the irradiation correlates with F-center concentration and further the hardening is not directly due to F-centers but due to other factors like interstitials which have the same concentration as F-centers. Sirdeshmukh et al. [27] also suggested that the radiation hardening is due to the role of radiation-induced defects other than F-centers. F-centers are so weak to interact with dislocation that they do not act as obstacles to dislocation motion [28]. This would be because F-center has isotropic defect. Hole-center such as $\mathrm{V}_{2}$-center, which is observed in the spectra of the $\mathrm{X}$-ray irradiated $\mathrm{KBr}$ in Fig. 1, has not isotropic but is considered to have tetragonal distortion. With regard to the spectra of $\mathrm{NaBr}$ irradiated with the $\mathrm{X}$-ray, the peak of it is not clear within the measurement. The irradiation-induced lattice defects act as weak obstacles to dislocation motion. This could lead to the appearance of $\tau_{\mathrm{p}}$ on the relative curve of $\lambda$ and $\Delta \tau$ at low temperature for the $\mathrm{X}$-irradiated $\mathrm{KBr}$ and $\mathrm{NaBr}$.

\section{Interaction between dislocation and the radiation-induced defects}

The force-distance profile between screw dislocation and tetragonal defect was reported by Barnett and Nix [29]. On the assumption that the force-distance profile derived by Barnett and Nix can be applied to the $\mathrm{X}$-irradiated $\mathrm{KBr}$ and $\mathrm{NaBr}$, the interaction Figure $8 \mathrm{a}, \mathrm{b}$ between dislocation and the radiation-induced defects is studied as below. Fig. $8 \mathrm{a}$ and $\mathrm{b}$ shows the relation between $\tau_{\mathrm{p}}$ and temperature for the crystals. The value of $\tau_{\mathrm{p}}$ tends to decrease with increasing temperature and appears to approach to zero at the critical

Figure $9 \mathrm{a}, \mathrm{b}$ temperature, $T_{\mathrm{c}}$, for both the crystals. Fig. 9a and b shows the dependence of the 
strain-rate sensitivity of flow stress due to point defects on temperature. The solid Figure 10a,b circles correspond to $\lambda_{\mathrm{p}}$ for the crystals. Fig. 10a and b shows the relation between $\tau_{\mathrm{p}}$ and activation volume $V$ (i.e. $k T / \lambda_{\mathrm{p}}$ ) for the $\mathrm{X}$-ray irradiated $\mathrm{NaBr}$ and $\mathrm{KBr}$. Figs 8 to 10 reflect the interaction between dislocation and defects. The solid curves in these figures are obtained as follows. When a dislocation breaks-away from weak obstacles dispersed in the lattice with the aid of thermal fluctuations under the effective stress $\left(\tau_{\mathrm{e}}\right)$, the activation energy $(G)$ at temperature $T$ is expressed by Eq. (2) [24]:

$$
G=\frac{T}{T_{c}} G_{0}
$$

where $T_{c}$ is the critical temperature at which $\tau_{\mathrm{e}}$ becomes zero and the dislocation breaks-away from the dopants only with the help of thermal activation, and $G_{0}$ the Gibbs free energy for overcoming of the dopant by dislocation at absolute zero. As a function of distance $\xi=x / b$ in units of $b$ from the position of defect on the slip plane $b$ away from it, the force $f$ acted on the dislocation is given by Eq. (3) [29, 30]:

$$
f=f_{0} \alpha^{3 / 2} \frac{\alpha \xi^{2}+2 \sqrt{2} \xi-1}{\left(\alpha \xi^{2}+1\right)^{2}}
$$

where $\alpha=\left(C_{11}-C_{12}\right) / 2 C_{44}$ the anisotropy factor, $f_{0}=\Omega \Delta \varepsilon C_{44} / 4 \pi b, \Omega$ the volume of the defect and $\Delta \varepsilon=\varepsilon_{11}-\varepsilon_{22}$ the tetragonality. When the dislocation moves under $\tau_{\mathrm{e}}$ at $T$, the force $f_{e}$ is acted on the defect. The value of $f_{e}$ is numerically calculated 
using Eqs. (2) and (3) with parameters of appropriate $T_{\mathrm{c}}$ and $G_{0}$ so that the area surrounded by the force-distance curve of Eq. (3) (i.e. Barnett-Nix relation) and the straight line of $f=f_{e}$ satisfies $G$. $\tau_{\mathrm{e}}$ is obtained from the Friedel relation [31]:

$$
\tau_{e}=\tau_{0}\left(\frac{f_{e}}{f_{m}}\right)^{3 / 2}
$$

where $\tau_{0}$ is the effective stress at absolute zero and replaced by $\tau_{\mathrm{p} 0}$ (value of $\tau_{\mathrm{p}}$ at absolute zero) and $f_{m}$ the maximum of $f \cdot \tau_{\mathrm{e}}$ at different strain-rate (i.e. different $T_{c}$ in Eq. (2)) is also calculated similarly and $\lambda\left(=\Delta \tau_{e} / \Delta \ln \dot{\varepsilon}\right)$ is estimated from the difference ( $\Delta \tau_{e}$ ) between the two $\tau_{\mathrm{e}}$ values. $V$ is obtained on the basis of $\Delta \tau_{e} / \Delta \ln \dot{\varepsilon}$. In this way $\tau_{\mathrm{e}}$ and $\lambda$ at a given temperature and further $V$ vs. $\tau_{\mathrm{e}}$ are represented as the solid curves in Figs 8 to 10, where the values of $G_{0}, \tau_{0}$ and $T_{c}$ are determined as to be fitted to the experimental results (i.e. solid circles in these figures) using the least squares method. These curves agree with the measured data analysed on the basis of $\Delta \tau$ versus $\lambda$ curves for the crystals. The parameters $\left(\tau_{\mathrm{p} 0}, T_{c}\right.$ and $\left.G_{0}\right)$ used for

Table 1 calculation are listed in Table 1 . The value of $G_{0}$ for the irradiated $\mathrm{KBr}$ is somewhat larger than for the $\mathrm{NaBr}$. This may suggest that the tetragonality around the $\mathrm{X}$-ray induced defect in the $\mathrm{KBr}$ is somewhat larger than in the $\mathrm{NaBr}$.

\section{Conclusion}

The strain-rate cycling tests associated with ultrasonic oscillation were carried out for the purpose of investigation on the interaction between dislocation and defects during 
plastic deformation of the $\mathrm{NaBr}$ and $\mathrm{KBr}$ single crystals irradiated with $\mathrm{X}$-ray at room temperature. On the basis of data analyzed in terms of $\lambda$ versus $\Delta \tau$ due to the oscillation, it is considered that the X-ray induced defects have weak interaction with dislocation and act as obstacles to dislocation motion. Then, the activation energy for the break-away of dislocation from the defect is found to be $0.76 \mathrm{eV}$ for $\mathrm{NaBr}$ and $0.81 \mathrm{eV}$ for $\mathrm{KBr}$. Furthermore, the values of $\tau_{\mathrm{p} 0}$ and $T_{\mathrm{c}}$ are also obtained through the study for the two kinds of crystals.

\section{Acknowledgements}

We would like to thank S. Matsumoto and H. Takeno for their experimental assistance.

\section{Compliance with ethical standards}

Conflict of interest The authors declare that they have no conflict of interest. 


\section{References}

[1] Meshii M (1968) Interaction of glide dislocations with interstitials and lattice vacancies. In: Proceedings of symposium on the interactions between dislocations and point defects, Harwell, pp 566-603

[2] Sibley WA and Sonder E (1963) Hardening of $\mathrm{KCl}$ by electron and gamma irradiation. J Appl Phys 34:2366-2370

[3] Nadeau JS (1964) Radiation hardening in alkali-halide crystals. J Appl Phys 35:1248-1255

[4] Reppich B (1971) Radiation hardening of alkali halides and magnesium oxide. Script Metall 5:289-293

[5] Tanimura K, Fujiwara M, Okada T, Hagihara $T$ (1978) Mechanism of low-temperature radiation hardening in alkali halides I Single halogen interstitials as the hardening agent at low temperature. J Appl Phys 49:5452-5456

[6] Tabachnikova ED, Podolskiy AV, Smirnov SN, Psaruk IA, Liao PK (2014) Temperature dependent mechanical properties and thermal activation plasticity of nanocrystalline and coarse grained Ni-18.75 at.\% Fe alloy. IOP conference series: Mater Sci Eng 63:012105

[7] Okazaki K (1996) Solid-solution hardening and softening in binary iron alloys. J Mater Sci 31:1087-1099

[8] Messerschmidt U (2010) Dislocation dynamics during plastic deformation. Springer-Verlag, Berlin Heidelberg

[9] Kataoka T, Ohji H, Kishida K, Azuma K, Yamada T (1990) Direct observation of glide dislocations in a $\mathrm{KCl}$ crystal by the light scattering method. Appl Phys Lett 56:1317-1319

[10] Kosugi T (2001) Temperature dependence of amplitude-dependent internal friction due to simultaneous breakaway of a dislocation from several pinning points. Mater Sci Eng A 309-310:203-206

[11] Gremaud G (2001) Dislocation-point defect interactions. Mater Sci Forum 366-368:178-246

[12] Urusovskaya AA, Petchenko AM, Mozgovoi VI (1991) The influence of strain rate on stress relaxation. Phys Status Solidi A 125:155-160

[13] V. I. Dotsenko (1979) Stress relaxation in crystals. Phys Status Solidi B 93:11-43

[14] Johnston WG, Gilman JJ (1959) Dislocation velocities, dislocation densities, and plastic flow in lithium fluoride crystals. J Appl Phys 30:129-143

[15] Granato AV, Lücke K (1956) Theory of mechanical damping due to dislocations. J Appl Phys 27:583-593

[16] Ohgaku T, Matsunaga T (2009) Interaction between dislocation and divalent impurity in $\mathrm{KBr}$ single crystals. IOP conference series: Mater Sci Eng 3:012021

[17] Kohzuki Y (2009) Study on the interaction between a dislocation and impurities in $\mathrm{KCl}: \mathrm{Sr}$ single crystals by the Blaha effect-Part IV influence of heat treatment on dislocation density. J Mater Sci 44:379-384

[18] Kohzuki Y (2010) Bending angle of dislocation pinned by an obstacle and the Friedel relation. Philos Mag 90:2273-2287

[19] Seitz F (1946) Color centers in alkali halide crystals. Rev Mod Phys 18:384-408

[20] Seitz F (1954) Color centers in alkali halide crystals II. Rev Mod Phys 26:7-93

[21] Klein MV, Kennedy SO, Gie TI, Wedding B (1968) The hydroxyl ion in alkali 
halide crystals-crystal growth and characterization. Mat Res Bull 3:677-686

[22] Markham JJ (1966) F-centers in alkali halides. Solid State Phys suppl 8, Academic Press, New York

[23] Sirdeshmukh DB, Sirdeshmukh L, Subhadra KG (2001) Alkali halides. Springer-Verlag, Berlin Heidelberg, p 41

[24] Conrad H (1964) Thermally activated deformation of metals. J Metals 16:582-588

[25] Kohzuki Y, Ohgaku T, Takeuchi N (1995) Interaction between a dislocation and various divalent impurities in KCl single crystals. J Mater Sci 30:101-104

[26] Nadeau JS (1962) Color centers and the flow stress of LiF single crystals. J Appl Phys 33:3480-3486

[27] Sirdeshmukh DB, Sirdeshmukh L, Subhadra KG (2006) Micro- and macro-properties of solids. Springer-Verlag, Berlin Heidelberg, p 176

[28] Zakrevskii VA, Shul'diner AV (2000) Dislocation interaction with radiation defects in alkali-halide crystals. Phys Sol Stat 42:270-273

[29] Barnett DM, Nix WD (1973) The interaction force between tetragonal defects and screw dislocations in cubic crystals. Acta Metall 21:1157-1168

[30] Mitchell TE, Heuer AH (1977) Solution hardening by aliovalent cations in ionic crystals. Mater Sci Eng 28:81-97

[31] Friedel J (1964) Dislocations. Pergamon Press, Oxford, pp 223-226 
Table 1 Parameters used for calculation

\begin{tabular}{lcrc}
\hline Crystal & $\tau_{\mathrm{p} 0}(\mathrm{MPa})$ & $T_{\mathrm{c}}(\mathrm{K})$ & $G_{0}(\mathrm{eV})$ \\
\hline X-Irr. $\mathrm{NaBr}$ & 1.99 & 369 & 0.76 \\
X-Irr. $\mathrm{KBr}$ & 0.67 & 660 & 0.81 \\
\hline
\end{tabular}


Figure captions

Figure 1 Absorption spectrum of X-ray irradiated $\mathrm{NaBr}$ and $\mathrm{KBr}$ single crystals.

Figure 2 Schematic illustration of the apparatus.

Figure 3 Variation of applied shear stress, $\tau_{\mathrm{a}}$, when the strain-rate cycling between the strain rates, $\dot{\varepsilon}_{1}\left(1.1 \times 10^{-5} \mathrm{~s}^{-1}\right)$ and $\dot{\varepsilon}_{2}\left(5.6 \times 10^{-5} \mathrm{~s}^{-1}\right)$, is carried out under superposition of ultrasonic oscillatory shear stress, $\tau_{\mathrm{v}}$.

Figure 4 Variation of (a) the stress decrement ( $\Delta \tau)$ and (b) the $\lambda\left(\Delta \tau^{\prime} / \Delta \ln \dot{\varepsilon}\right.$ ) of flow stress with shear strain at $173 \mathrm{~K}$ and various stress amplitude for $\mathrm{X}$-ray irradiated $\mathrm{NaBr}$ single crystal. The ultrasonic oscillatory stress $\left(\tau_{\mathrm{v}}\right)$ increases with its value (arb. units).

Figure 5 Relation between the $\lambda$ and the stress decrement $(\Delta \tau)$ for X-ray irradiated $\mathrm{NaBr}$ single crystal at $173 \mathrm{~K}$ and the strains of $15 \%$ and $20 \%$. The plotted points are obtained from Figure 4.

Figure 6 Relation between the $\lambda$ and the stress decrement ( $\Delta \tau)$ for X-ray irradiated $\mathrm{KBr}$ single crystal at various temperatures and strains.

Figure 7 Relation between the $\lambda$ and the stress decrement $(\Delta \tau)$ for a non-irradiated $\mathrm{KBr}$ single crystal at $193 \mathrm{~K}$ and the strains of 8-20\%.

Figure 8 Relation between $\tau_{\mathrm{p}}$ and temperature for X-ray irradiated (a) $\mathrm{NaBr}$ and (b) $\mathrm{KBr}$ single crystals. The solid curves are given by numerical calculation.

Figure 9 Dependence of $\lambda_{\mathrm{p}}$ on temperature for X-ray irradiated (a) $\mathrm{NaBr}$ and (b) $\mathrm{KBr}$ single crystals. The solid curves are given by numerical calculation.

Figure 10 Relation between $\tau_{\mathrm{p}}$ and activation volume for $\mathrm{X}$-ray irradiated (a) $\mathrm{NaBr}$ and (b) $\mathrm{KBr}$ single crystals. The solid curves are given by numerical calculation. 


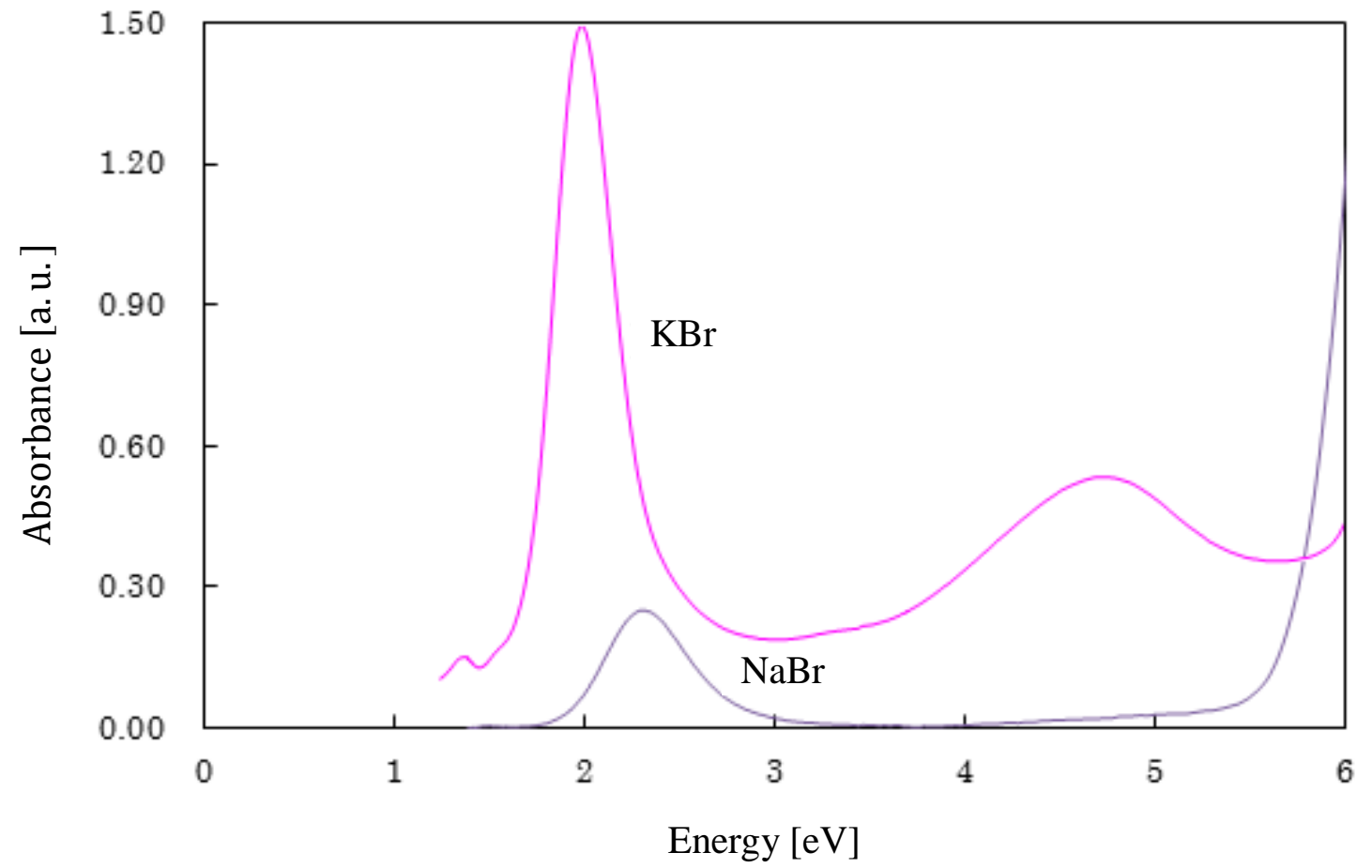

Figure 1 


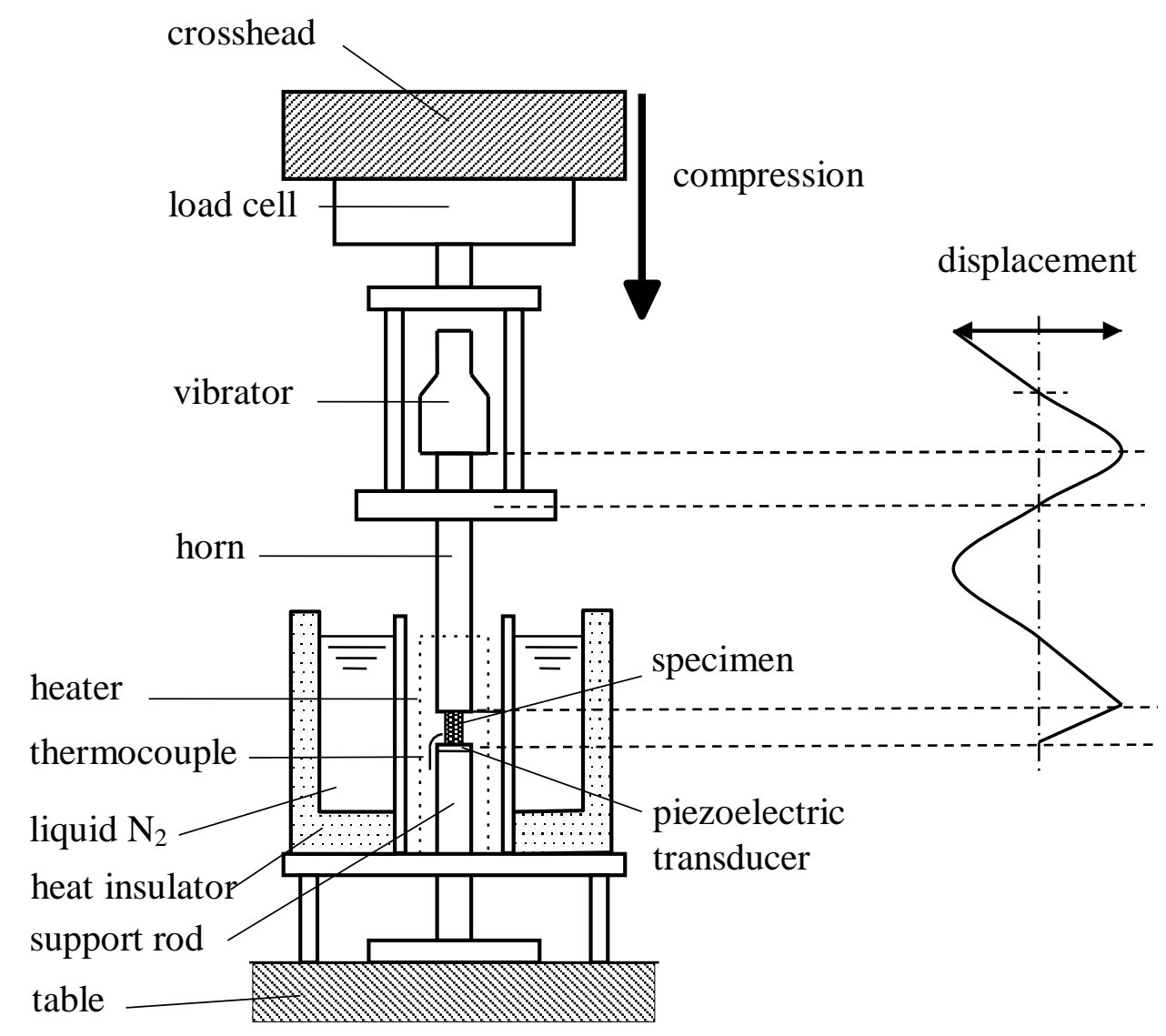

Figure 2

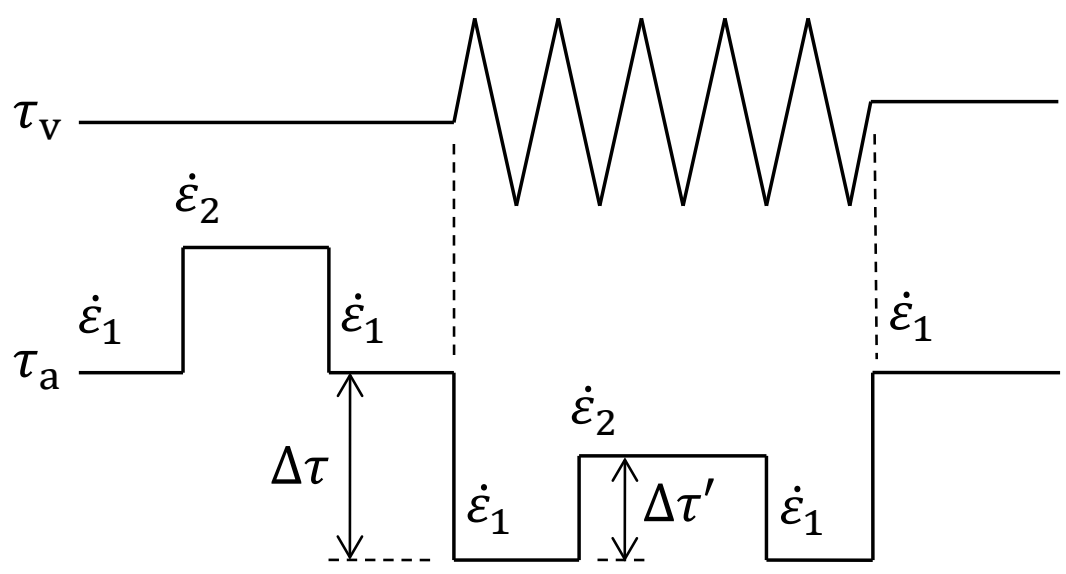

Figure 3 


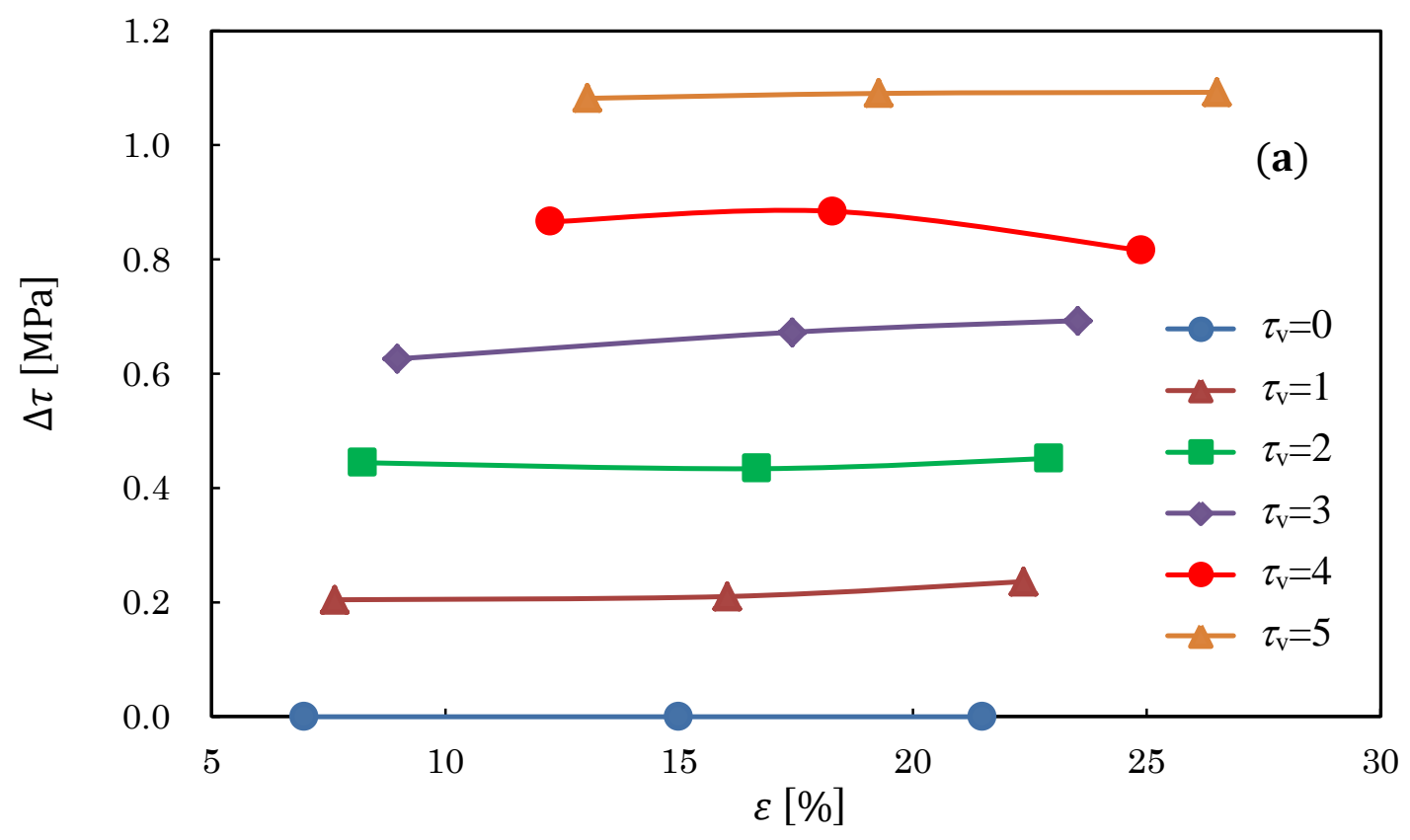

Figure 4 (a)

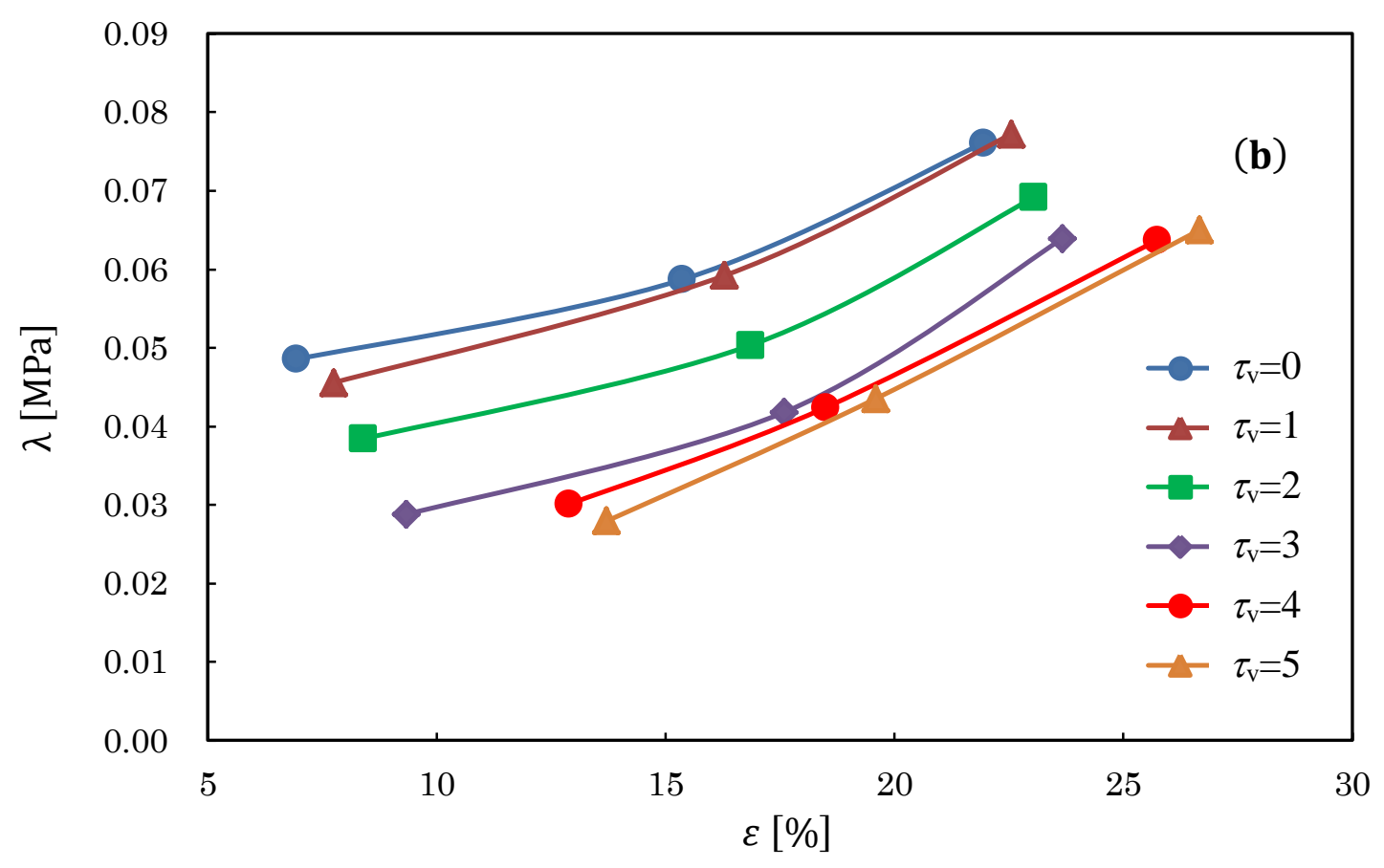

Figure 4 (b) 


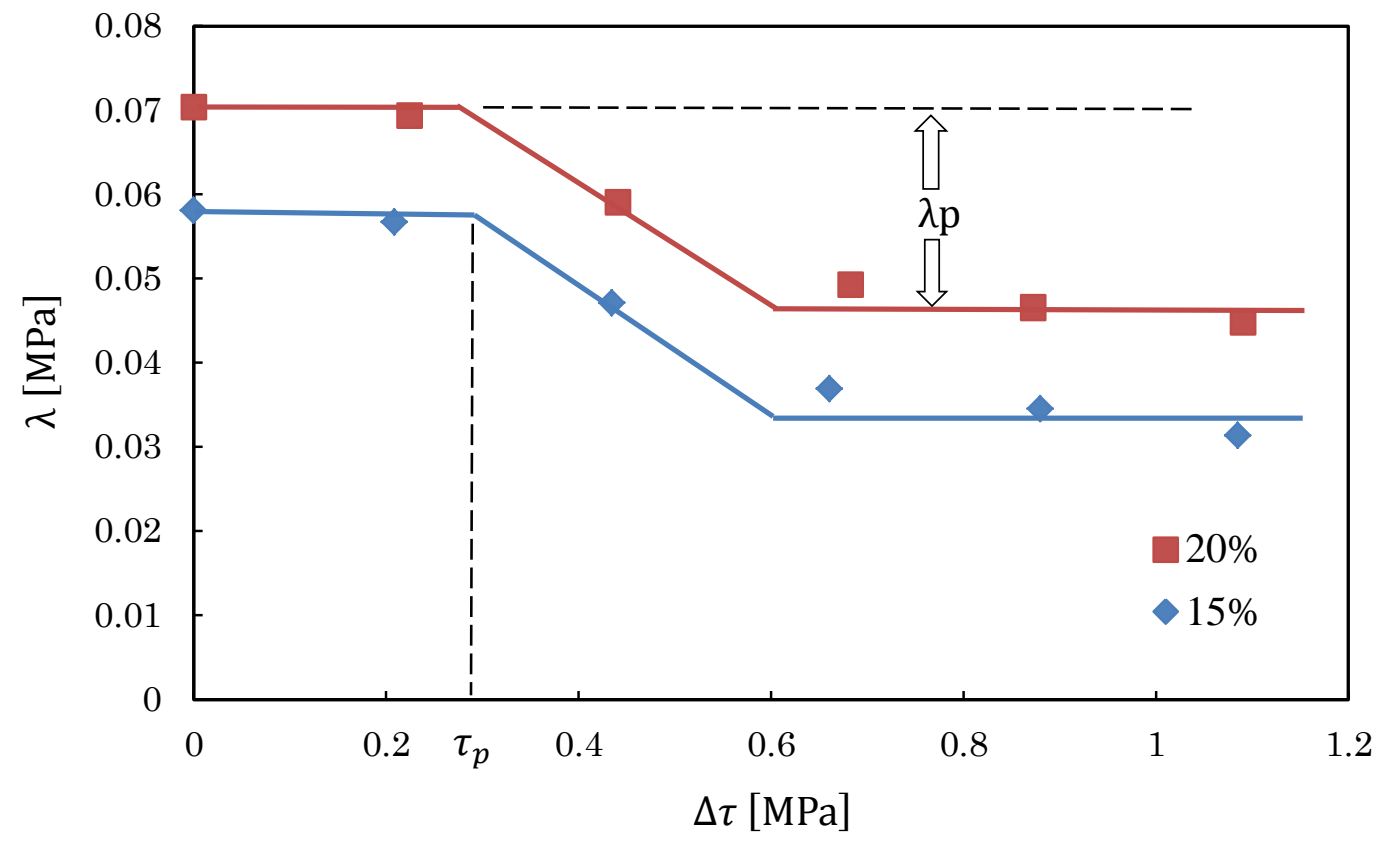

Figure 5

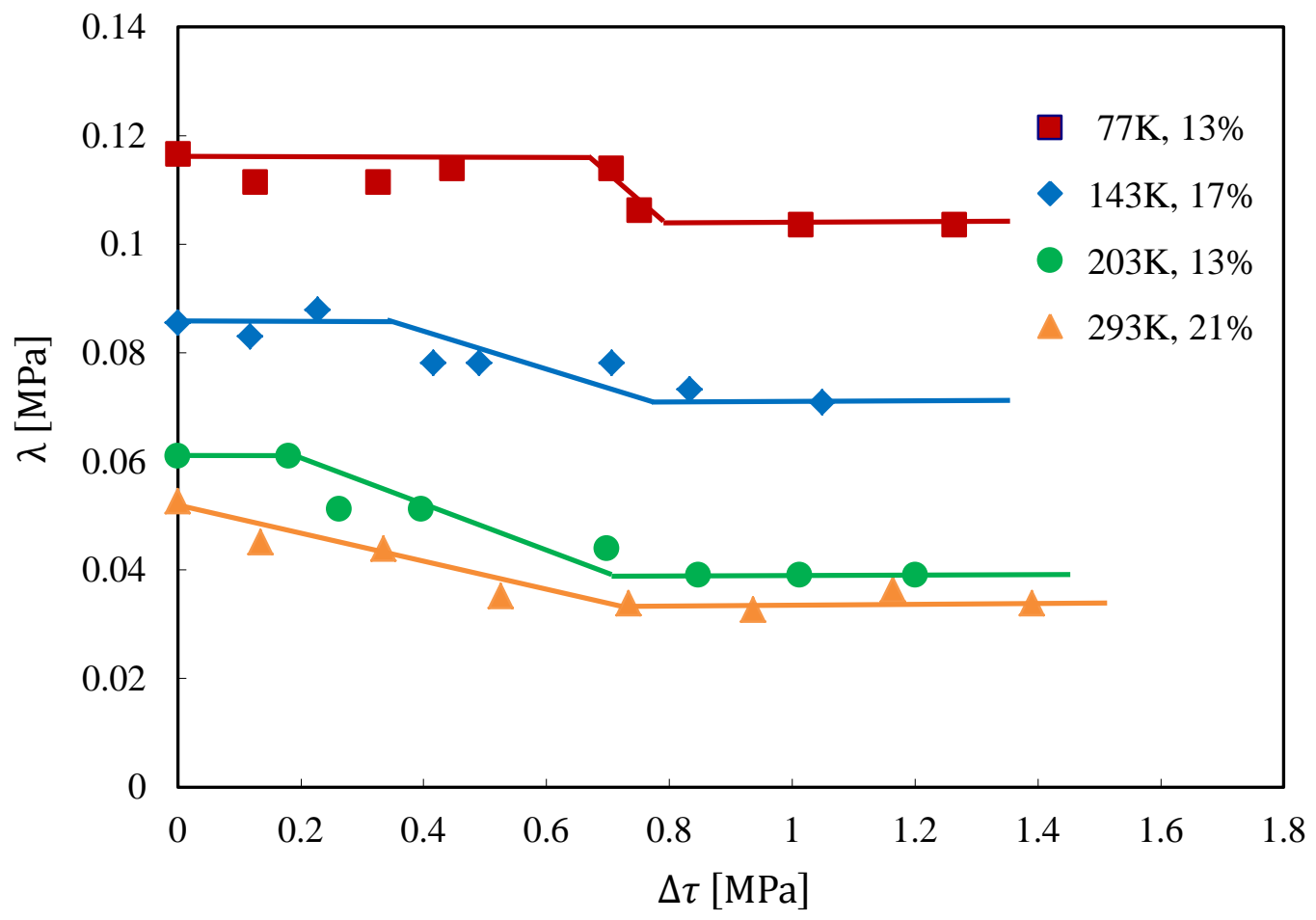

Figure 6 


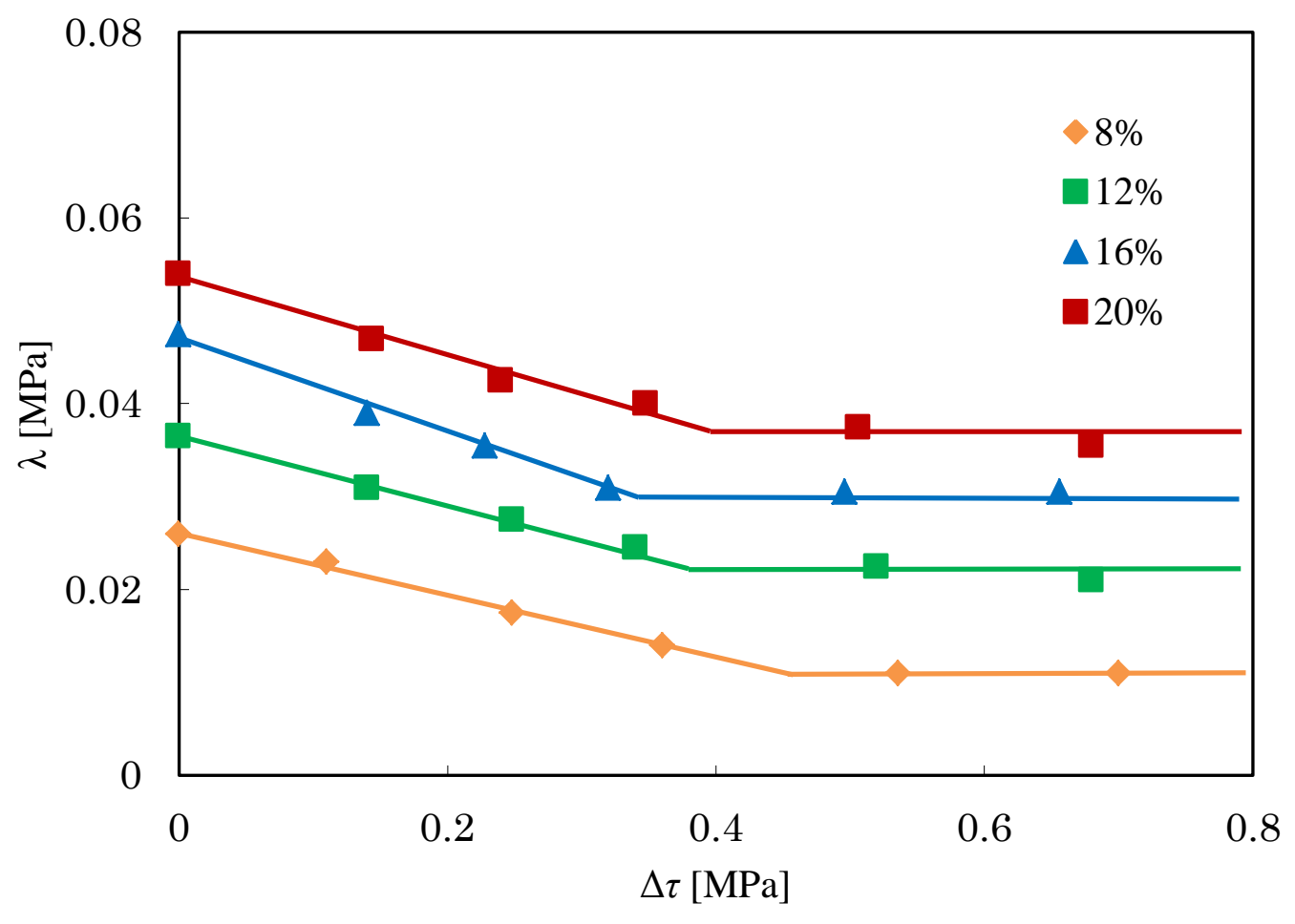

Figure 7

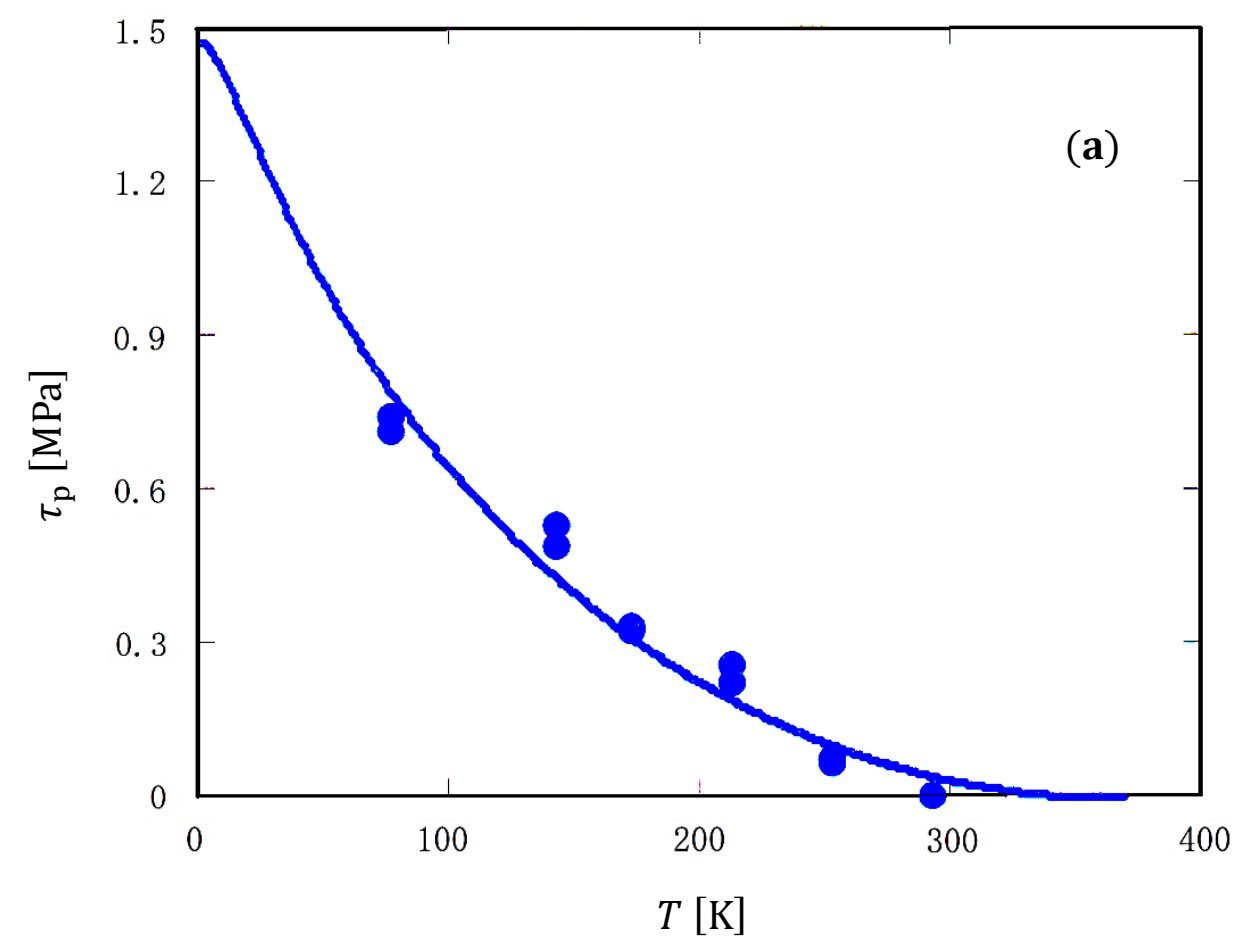

Figure 8 (a) 


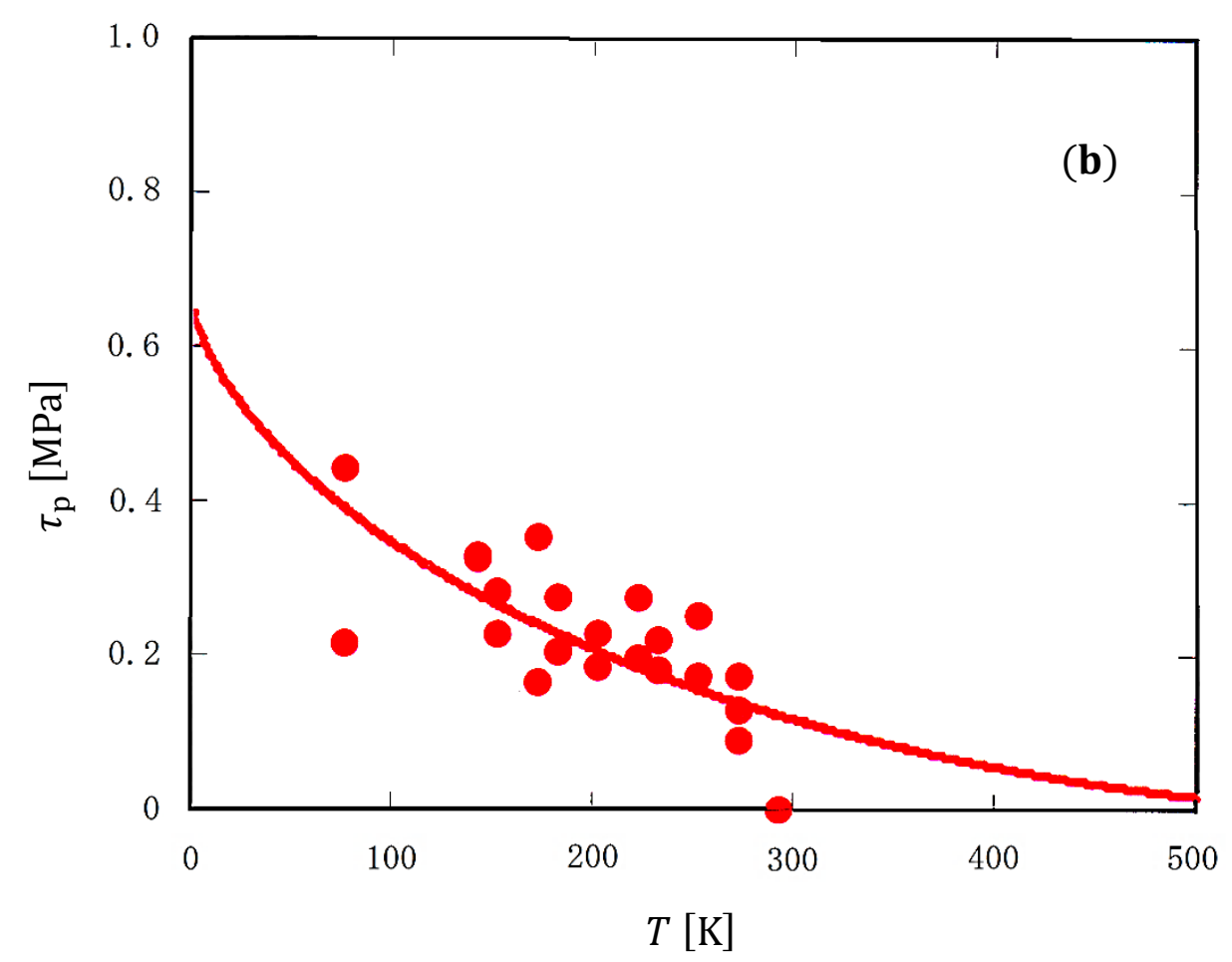

Figure 8 (b)

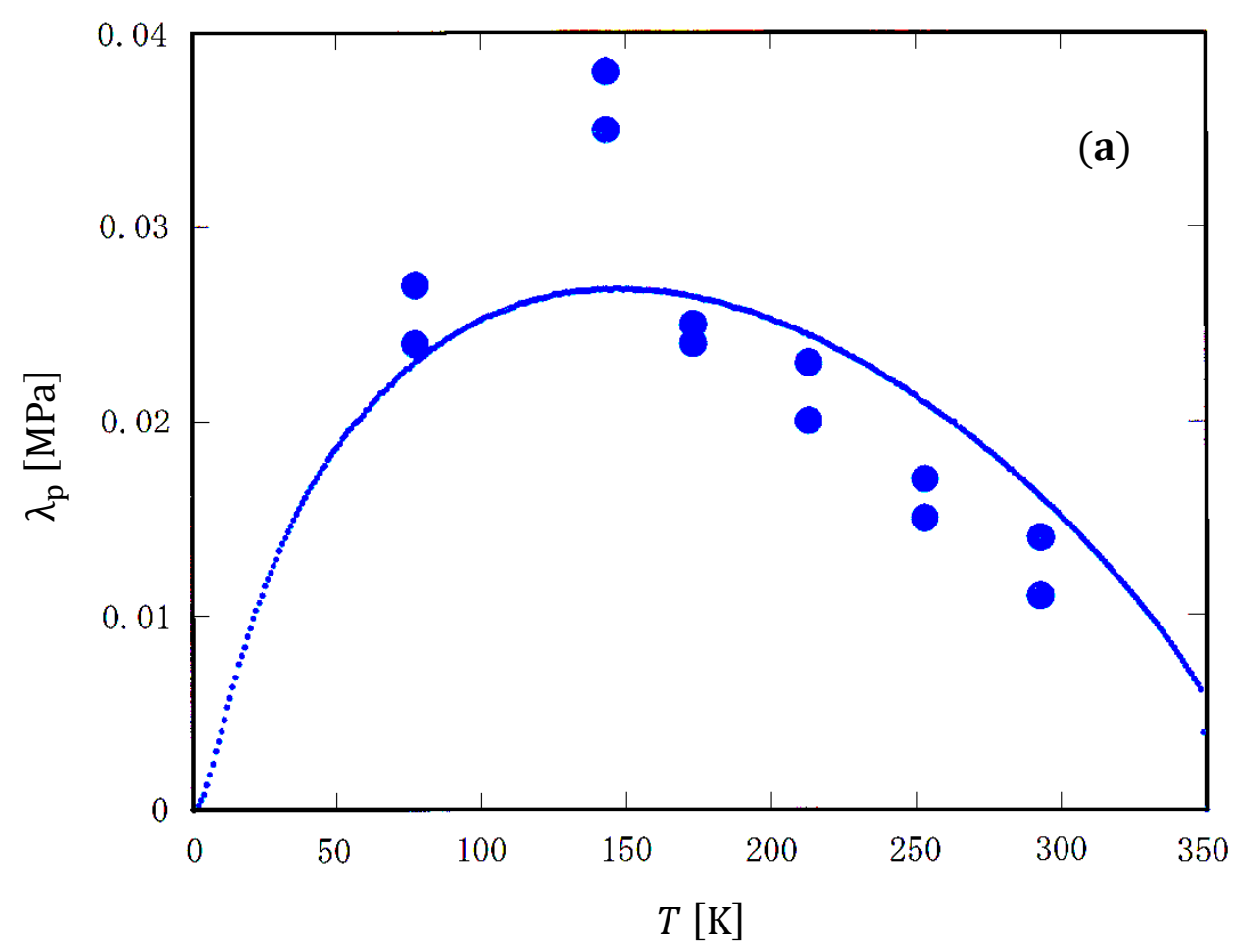

Figure 9 (a) 


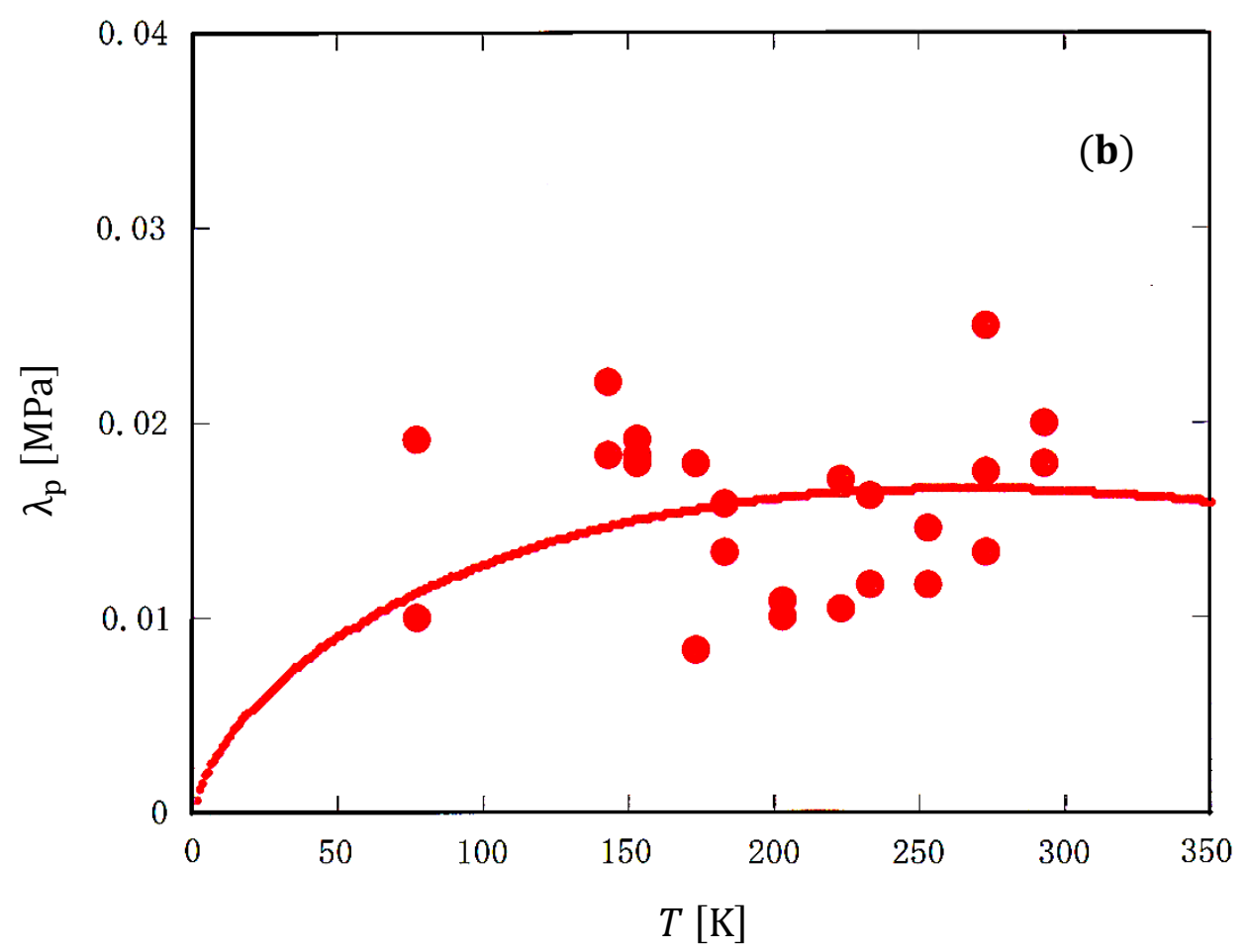

Figure 9 (b)

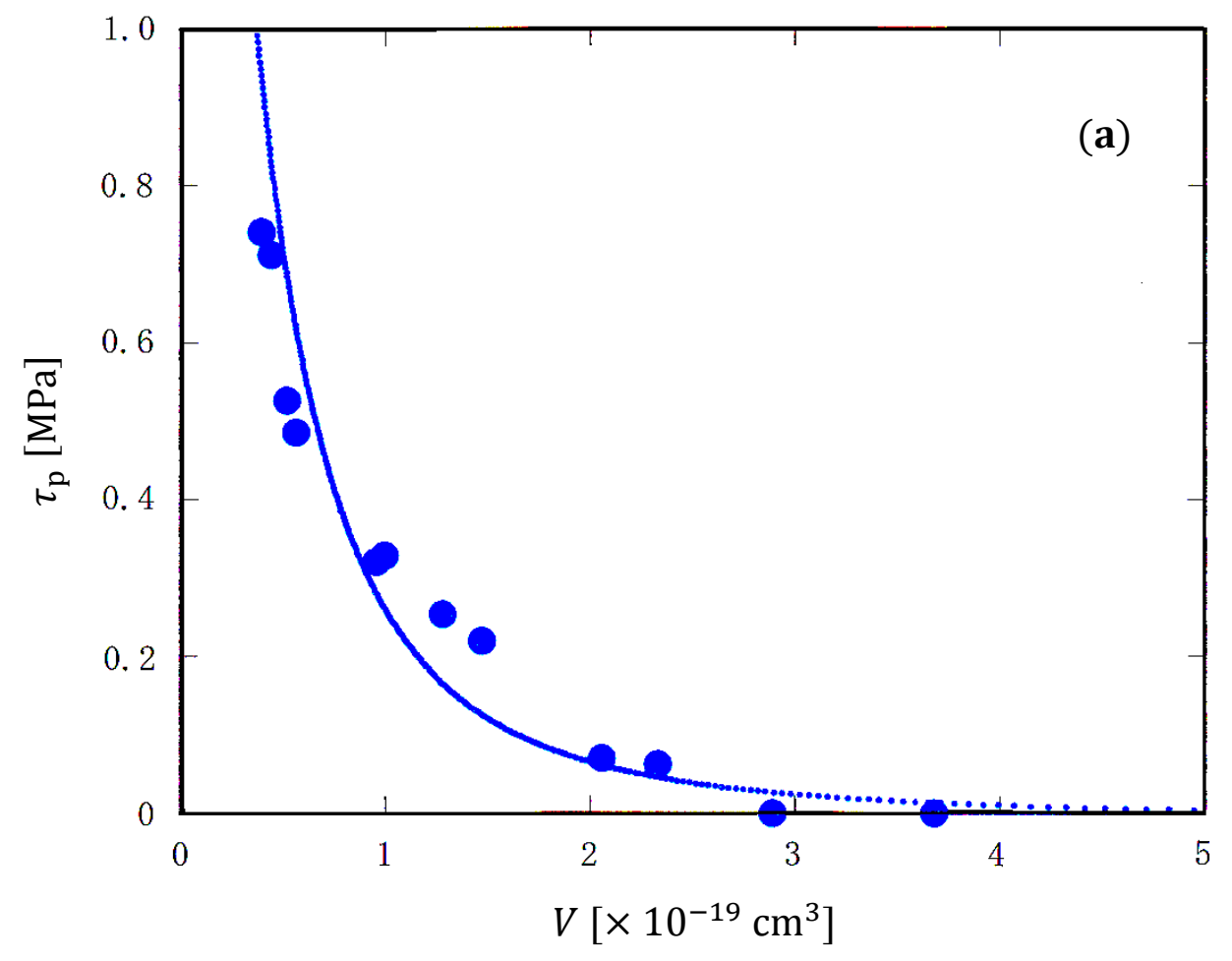

Figure 10 (a) 


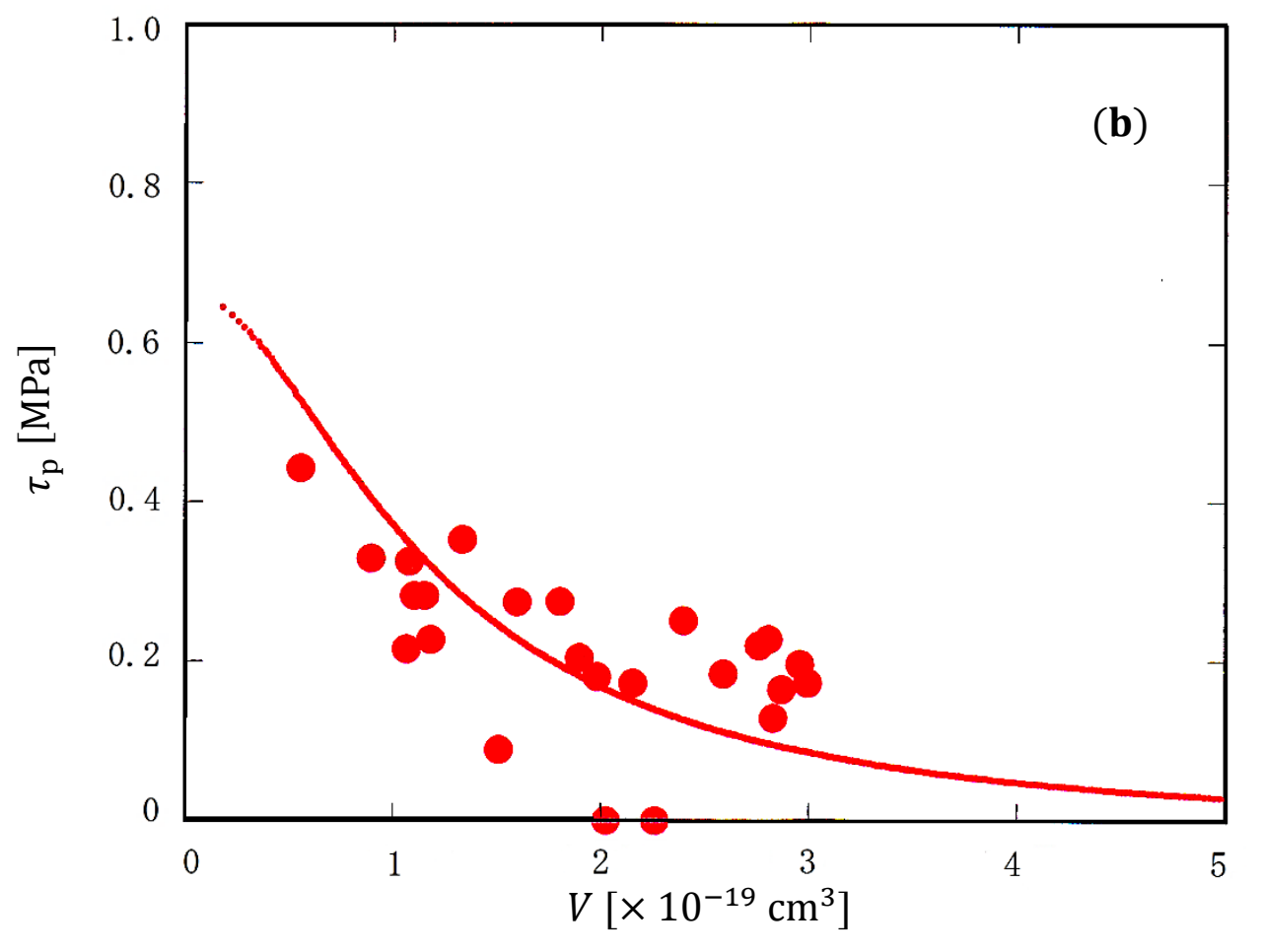

Figure 10 (b) 